\title{
Aggressive muscle-invasive bladder cancer with sarcomatoid differentiation in a 10-year-old girl: A case report
}

\author{
ZIJIAN WANG, WEI XIONG, CIZHONG PAN, LIANG ZHU, XINJUN WANG, \\ ZHICHAO HUANG, XIAOKUN ZHAO and ZHAOHUI ZHONG
}

Department of Urology, The Second Xiangya Hospital, Central South University, Changsha, Hunan 410011, P.R. China

Received November 19, 2014; Accepted October 27, 2015

DOI: $10.3892 /$ etm.2016.3012

\begin{abstract}
The present study reports an unusual case of high-grade bladder cancer in a 10-year-old girl who complained of painless hematuria and urinary frequency. The tumor displayed sarcomatoid differentiation and an aggressive behavior, which required the administration of adjuvant chemotherapy. However, the disease progressed and the patient succumbed 6 months after surgery. It is known that the majority of malignant bladder cancers in pediatric patients are low-grade and present at an early stage, whereas sarcomatoid differentiation in the setting of a high-grade urothelial carcinoma is indicative of a poor prognosis. It is important that gross hematuria in pediatric patients is investigated carefully. It is recommended that the management of urothelial neoplasia in young patients should be predominantly decided on the basis of the grade and stage of the tumor rather than the age of the patient.
\end{abstract}

\section{Introduction}

The presentation of bladder cancer is rare $(0.038 \%)$ in the first two decades of an individual's life, particularly until the age of 10 years $(1,2)$. As such, the literature on this topic is very limited, with only a small number of cases having been previously described (3). Furthermore, to the best of our knowledge, the majority of these previously reported cases have been early-stage, low-grade carcinomas that were treated with transurethral resection with a favorable outcome in patients $<25$ years-of-age $(4,5)$. Transitional cell carcinomas in children have been shown to have a less aggressive nature, as compared with the same carcinomas in adults (4). In adults, management of bladder carcinoma involves transurethral resection for non-invasive lesions,

Correspondence to: Professor Xiaokun Zhao, Department of Urology, The Second Xiangya Hospital, Central South University, 139 Renmin Road, Changsha, Hunan 410011, P.R. China E-mail: xiaokunzhao@126.com

Key words: bladder cancer, radical cystectomy, adjuvant therapy, children and a cystectomy in cases of muscle invasion. In addition, surgery is typically followed by intravesical chemotherapy and/or immunotherapy in order to control any microscopic residuals (6). Both the American Urological Association and the International Consultation on Bladder Cancer 2012 suggested that intravesical mitomycin installation into the bladder should occur immediately following the transurethral resection of papillary lesions. Furthermore, for cases of high-grade disease, a cytoscopy and re-resection of the resected areas should occur at 6 weeks following the initial resection $(7,8)$. However, such recommendations do not seem justified for children, who appear to have clinical features that differ from adult patients and a better prognosis (4). The present study reports a rare case of bladder cancer identified in a 10-year-old female patient, which, apart from exhibiting high-grade histological features, also presented sarcomatoid differentiation with aggressive characteristics.

\section{Case report}

A 10-year-old female patient was referred to The Second Xiangya Hospital of Central South University (Changsha, China) presenting with painless hematuria and urinary frequency for 4 months. The patient had previously been diagnosed with urinary tract infection at a local hospital, and antibiotics had been prescribed. Physical examination revealed no abnormalities and a blood test showed a normal white blood cell count. However, a urinalysis detected white blood cells [1+/high power objective (HP)], red blood cells $(4+/ \mathrm{HP})$ and bacteriuria (2+), which suggested that the patient had severe hematuresis associated with infection.

Chest X-ray and bone scan images were normal. An abdominal computed tomography (CT) scan demonstrated a mass in the posterior bladder wall with a rough edge; no lymphadenopathy was found. Cystoscopy revealed a reddish, broccoli-like broad-based tumor in the posterior bladder wall (Fig. 1). Biopsy indicated a high-grade muscle-invasive urothelial carcinoma.

A traditional radical cystectomy was performed, although, due to the age of the patient, the internal genitalia were maintained in order to preserve the fertility of the patient. Briefly, following a bilateral pelvic lymphadenectomy, the superior vesical pedicles were ligated and divided on both sides. The blood supply to both the ovaries and 


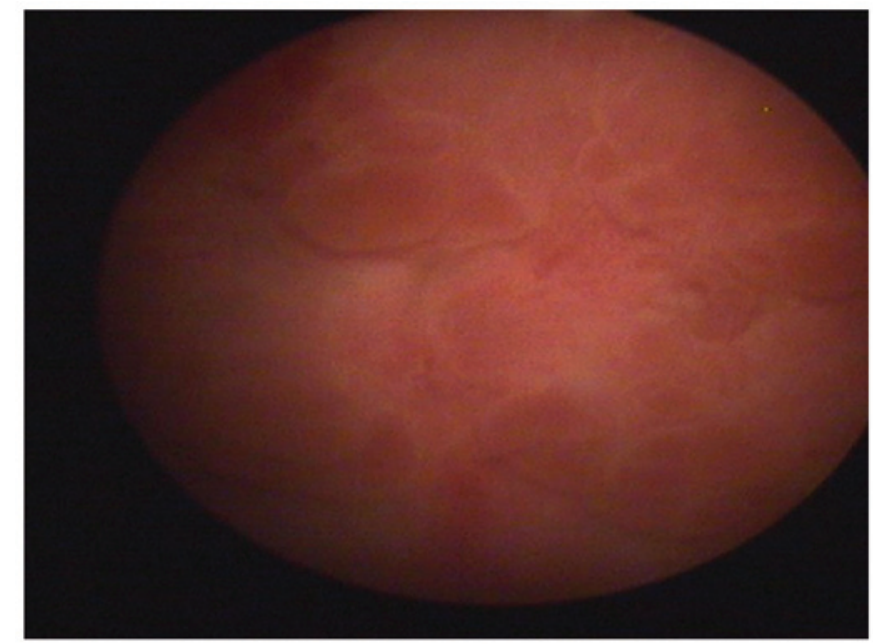

Figure 1. Cystoscopy revealed the presence of a tumor in the posterior bladder wall $(68 \times 55 \mathrm{~mm})$.

A

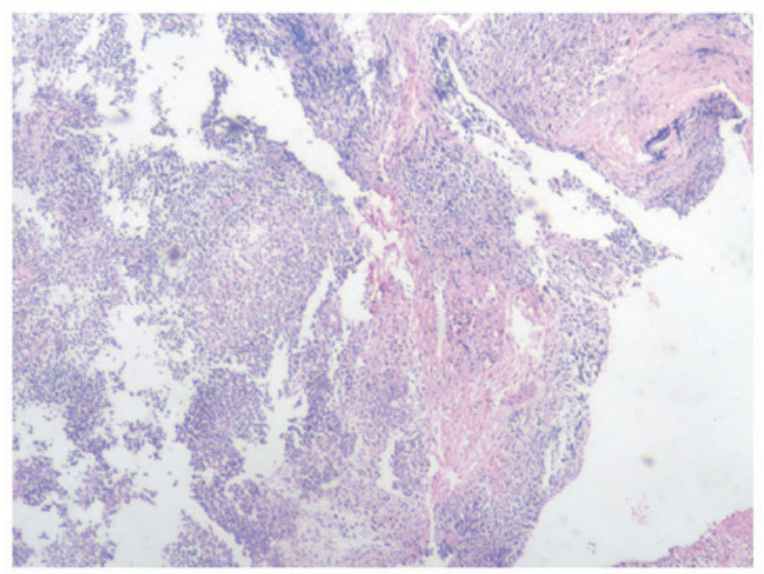

B

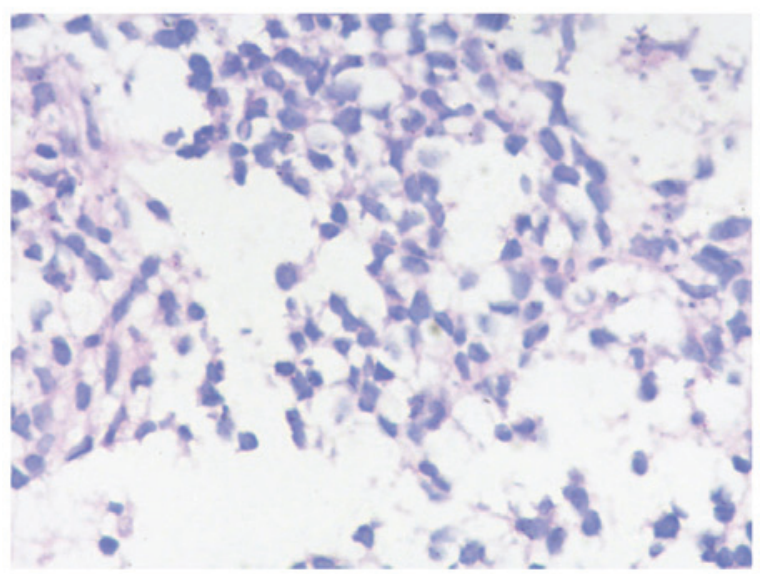

Figure 2. Histopathological examination characterized the tumor as a high-grade (grade 3) muscle-invasive urothelial carcinoma that extended from the (A) overlying epithelial surface (H\&E staining; magnification, $\mathrm{x} 40$ ), and comprised (B) areas of osseous and chondroid differentiation (H\&E staining; magnification, $\mathrm{x} 400$ ). H\&E, hematoxylin and eosin.

uterus was preserved, and a plane was constructed between the uterus and bladder and later was mobilized along with a small strip of anterior vaginal wall. Subsequently, a cystectomy combined with a urethrectomy was conducted, and an ileal conduit was made.
Upon gross examination, a 60x55 mm broad-based tumor was found in the posterior bladder wall. Subsequently, the cancer tissue was fixed in $10 \%$ formalin and dehydrated using an alcohol gradient, after which it was made transparent using xylene and embedded in paraffin (all: Sinopharm Chemical Reagent Co., Ltd., Shanghai, China). The paraffin-embedded tissue was then cut into 5-8 $\mu \mathrm{m}$ sections using the VIP 6-E2 Vacuum Infiltration Tissue Processor (Sakura Finetek USA, Inc., Torrance, CA, USA), and stained with hematoxylin and eosin (Beyotime Institute of Biotechnology, Haimen, China). Subsequently, the tissue sections were dehydrated using alcohol, made transparent with xylene and mounted using Canada balsam (Qiyun Biotechnology Co., Ltd., Guangzhou, China), prior to visualization under an optical microscope (Olympus BX41; Olympus Corporation, Tokyo, Japan). The histopathological findings suggested that the tumor was a grade 3 muscle-invasive urothelial carcinoma with sarcomatoid differentiation, according to the World Health Organization 1973 grading system (9). The TNM classification of the tumor was T2bN0M0 (10). Both ureter edges were clear, and the lymph nodes surrounding the iliac arteries and obtuator lymph nodes were negative (Fig. 2). Adjuvant chemotherapy, including methotrexate (Jiangsu Hengrui Medicine Co., Ltd., Lianyungang, China) vinblastine, adriamycin and cisplatin (all Shenzhen Main Luck Pharmaceuticals Inc., Shenzen, China), was administered 3 weeks after surgery; however, after receiving 4 cycles of chemotherapy, a CT scan of the abdomen identified disease progression and the patient succumbed 2 months later. The patient survived for only 6 months after surgery.

\section{Discussion}

The present case report describes a rare case of aggressive bladder carcinoma in a pediatric patient. The most important features of the case include the histopathological findings of the tumor, which revealed divergent differentiation, and fast disease progression following surgery. Despite the immediate administration of chemotherapy following surgery, the treatment was not beneficial for the patient.

The presentation of urothelial carcinoma of the bladder is rare in pediatric patients, accounting for $\sim 0.4 \%$ of cases (11). To the best of our knowledge, all reported bladder cancer cases in young people have been of low grade and low malignancy potential, with favorable outcomes $(12,13)$, and the majority of them were treated with transurethral resection of the bladder tumor without any kind of adjuvant therapy (5). From a histological point of view, mesenchymal components can sometimes be found in high-grade bladder cancer, which usually indicates poor prognosis (14). This was the case in the present patient, for whom multiple mesenchymal components were found in a high-grade urothelial carcinoma.

Gross hematuria is a common symptom of bladder cancer in both pediatric and adult patients. In many cases, gross hematuria leads to a misdiagnosis of urinary tract infection or urinary stone disease $(15,16)$, and thus, the underlying condition remains unidentified. Risk factors for bladder cancer in pediatric patients are not clear. A review in which multiple cases of bladder cancer within families were analyzed suggested that there might be a genetic predisposition for this 
disease; however, it remains unclear whether multiple bladder cancer cases within families are a result of genetic predisposition or due to shared environmental exposure among family members (17).

There is no guideline available for the treatment and follow-up of high-grade bladder cancer in pediatric patients. The outcome of radical cystectomy is unpleasant, including a poor quality of life, poor prognosis and reduced fertility in women (18). However, radical cystectomy combined with adjuvant therapy (chemotherapy and/or radiation therapy) is currently the primary treatment option for invasive high-grade bladder cancer (19). Fertility-preserving radical cystectomy and chemotherapy have been reported in young females (20) and children (21). Lymph node involvement has been reported to be the most important predictive factor for cancer recurrence (22); however, no evidence of lymph node involvement was identified in the present case during surgery.

In conclusion, it is important to consider carefully presentations of gross hematuria in pediatric patients. It is recommended that the management of urothelial neoplasia in young patients should largely depend on the tumor's grade and stage, rather than on the age of the patient. The use of radical cystectomy combined with adjuvant therapy in pediatric patients is controversial due to a lack of guidelines for the management and follow-up of these patients; however, it continues to be a viable option for the treatment of high-grade muscle-invasive bladder cancer in children.

\section{References}

1. Serrano-Durbá A, Domínguez-Hinarejos C, Reig-Ruiz C, Fernández-Córdoba $\mathrm{M}$ and García-Ibarra F: Transitional cell carcinoma of the bladder in children. Scand J Uro Nephrol 33: 73-76, 1999.

2. Thomas G, Gera P, Arbuckle S and Cohen R: Transitional cell papilloma of the bladder in a child: A case report and review of literature. J Pediatr Urol 2: 59-62, 2006

3. Bujons A, Caffaratti J, Garat JM and Villavicencio $\mathrm{H}$ : Long-term follow-up of transitional cell carcinoma of the bladder in childhood. J Pediatr Urol 10: 167-170, 2014.

4. Yusim I, Lismer L, Greenberg G, Haomud K and Kaneti J: Carcinoma of the bladder in patients under 25 years of age. Scand J Urol Nephrol 30: 461-463, 1996.

5. Hoenig DM, McRae S, Chen SC, Diamond DA, Rabinowitz R and Caldamone AA: Transitional cell carcinoma of the bladder in the pediatric patient. J Urol 156: 203-205, 1996.

6. Resnick MJ, Bassett JC and Clark PE: Management of superficial and muscle-invasive urothelial cancers of the bladder. Curr Opin Oncol 25: 281-288, 2013.
7. Malmström PU, Sylvester RJ, Crawford DE, Friedrich M, Krege S, Rintala E, Solsona E, Di Stasi SM and Witjes JA: An individual patient data meta-analysis of the long-term outcome of randomised studies comparing intravesical mitomycin $\mathrm{C}$ versus bacillus Calmette-Guérin for non-muscle-invasive bladder cancer. Eur Urol 56: 247-256, 2009.

8. Fine SW, Humphrey PA, Dehner LP, Amin MB and Epstein JI: Urothelial neoplasms in patients 20 years or younger: A clinicopathological analysis using the world health organisation 2004 bladder consensus classification. J Urol 174: 1976-1980, 2005.

9. World Health Organization (WHO): Histological typing of urinary bladder tumors. WHO, Geneva pp237-256, 1973

10. International Union Against Cancer (UICC): TNM classification of malignant tumors. 7th edition. UICC, Genewa, Switzerland pp262-265, 2009.

11. Poddevin F and Bayart M: Urothelial tumor of the bladder in children. J Urol (Paris) 101: 191-194, 1995 (In French).

12. Williamson SR, Lopez-Beltran A, MacLennan GT, Montironi R and Cheng L: Unique clinicopathologic and molecular characteristics of urinary bladder tumors in children and young adults. Urol Oncol 31: 414-426, 2013.

13. Fine SW, Humphrey PA, Dehner LP, Amin MB and Epstein JI: Urothelial neoplasms in patients 20 years or younger: A clinicopathological analysis using the World Health Organization 2004 bladder consensus classification. J Urol 174: 1976-1980, 2005.

14. Patel R, Tery T and Ninan GK: Transitional cell carcinoma of the bladder in first decade of life. Pediatr Surg Int 24: 1265-1268, 2008.

15. Ristic-Petrovic A, Stojnev S, Janković-Velickovic L and Marjanovic G: Malakoplakia mimics urinary bladder cancer: A case report. Vojnosanit Pregl 70: 606-608, 2013.

16. Gedikoğlu G, Sökmensüer C, Söylemezoğlu F and Koçal C: Carcinosarcoma of the urinary bladder. Int Urol Nephrol 28: 333-336, 1996.

17. Mueller CM, Caporaso N and Greene MH: Familial and genetic risk of transitional cell carcinoma of the urinary tract. Urol Oncol 26: 451-464, 2008.

18. Yossepowitch O and Dalbagni G: Transitional cell carcinoma of the bladder in young adults: Presentation, natural history and outcome. J Urol 168: 61-66, 2002.

19. World Health Organization (WHO) Consensus Conference on Bladder Cancer; Hautmann RE, Abol-Enein H, Hafez K, Haro I, Mansson W, Mills RD, Montie JD, Sagalowsky AI, Stein JP, Stenzl A, et al: Urinary diversion. Uro 69 (1 Suppl): 17-49, 2007.

20. Gupta NP, Ansari MS, Khaitan A and Dawar R: Fertility preserving radical cystectomy in a young female with malignant mesenchymal tumour of urinary bladder. Int Urol Nephrol 35: 501-502, 2003.

21. Neogi S, Kariholu PL, Dhakre G, Gupta V, Agarwal N and Bhadani P: Malignant urothelial carcinoma of urinary bladder in a young child: A rare case report. Urology 81: 888-890, 2013.

22. Skinner DG, Daniels JR, Russell CA, Lieskovsky G, Boyd SD, Nichols P, Kern W, Sakamoto J, Krailo M and Groshen S: The role of adjuvant chemotherapy following cystectomy for invasive bladder cancer: A prospective comparative trial. J Urol 145: 459-467, 1991. 